American Journal of Pharmaceutical Education 2019; 83 (4) Article 7245.

\title{
COMMENTARY
}

\section{The Need for Faculty Knowledge and Promotion of Postgraduate Year One Community-Based Pharmacy Residencies}

\author{
Jean-Venable R. Goode, PharmD, ${ }^{a}$ Marialice S. Bennett, BSPharm, ${ }^{b}$ Anne L. Burns, BSPharm, ${ }^{c}$ \\ James A. Owen, PharmD ${ }^{\mathrm{c}}$ \\ ${ }^{a}$ Virginia Commonwealth University, School of Pharmacy, Richmond, Virginia \\ $\mathrm{b}$ The Ohio State University, College of Pharmacy, Columbus, Ohio \\ ${ }^{c}$ American Pharmacists Association, Washington, DC \\ Submitted June 2018; accepted January 28, 2019; published May 2019.
}

Postgraduate year one (PGY1) community-based pharmacy residency programs are intended to build upon the Doctor of Pharmacy (PharmD) education and outcomes. The goal of the residency program is to develop community-based pharmacist practitioners with diverse patient care, leadership, and education skills. This commentary will inform faculty mentors about the history, evolution, structure, and design of PGY1 community-based pharmacy residency programs. This commentary will also review the equivalency of PGY1 community-based pharmacy residency programs to other PGY1 programs, specifically to PGY1 pharmacy programs typically administered in hospitals and health systems. Faculty who are knowledgeable about PGY1 community-based pharmacy residency programs will be able to provide mentorship and promotion for student pharmacists who are interested in direct patient care.

Keywords: community-based, residency, faculty mentor, student pharmacist

\section{INTRODUCTION}

Entry-level positions in the profession of pharmacy are becoming more competitive due to an increasing number of Doctor of Pharmacy graduates in the marketplace. To differentiate themselves, student pharmacists are seeking opportunities for postgraduate education and training through residencies, fellowships, and graduate programs. The number of student pharmacists seeking these opportunities far exceeds the number of available residency and fellowship positions. Student pharmacists are often highly dependent on faculty mentors for guidance and direction regarding the types of residencies to pursue and how to successfully navigate the recruitment process. Faculty mentors should provide fair and balanced, unbiased information to mentees regarding the full spectrum of training options specifically in first-year residency training. Anecdotal observation reveals that student pharmacists are not often adequately informed by their faculty mentors about postgraduate year 1 (PGY1) community-based pharmacy residency programs (formerly known as PGY1 community pharmacy residency), which diminishes student awareness and the relative importance of these programs. The American Society of Health-System Pharmacists (ASHP) National Matching

Corresponding Author: Jean-Venable R. Goode, Virginia Commonwealth University, 410 North $12^{\text {th }}$ Street, Richmond, VA 23298. Tel: 804-828-3865. E-mail: jrgoode@vcu.edu.
Data supports a potential lack of knowledge with 5,000 applicants in 2018, 28\% of PGY1 community-based pharmacy residencies were unfilled after the Phase I Match compared to $3 \%$ of PGY1 pharmacy residencies and in Phase II $14 \%$ and $0.03 \%$, respectively. ${ }^{1}$

This commentary is intended to inform faculty mentors about the history, evolution, structure, design, and equivalency of PGY1 community-based pharmacy residency programs (CPRPs) to other PGY1 programs, specifically to PGY1 pharmacy residency programs (PRPs) typically administered in hospitals and health systems. Faculty who are knowledgeable about PGY1 CPRPs will be able to provide mentorship and promotion for student pharmacists who are interested in direct patient care. This full range of accurate and timely information regarding all first-year residency training options will allow student pharmacists to make educated decisions about the best training programs to pursue for their desired professional career paths.

\section{History of PGY-1 Community-Based Pharmacy Residency Programs (CPRPs)}

PGY1 CPRPs are relatively new on the program evolutionary timeline. ${ }^{2}$ In comparison, hospital/healthsystem programs originated in the 1930s, with the first programs in hospitals becoming accredited in $1962 .^{3}$ Community residency program development can be 


\section{American Journal of Pharmaceutical Education 2019; 83 (4) Article 7245.}

traced back to a forum held at the American Pharmacists Association (APhA) 1982 Annual Meeting which resulted in recommendations to develop and implement residency programs in the community setting and supported by policy passed by the 1984 APhA House of Delegates. $^{4,5}$ Afterward, APhA published a document outlining the objectives, skills, and outcomes for community pharmacy residency training, including management, drug distribution, clinical services, drug informatics, home health care and long-term care. ${ }^{6}$ It also provided the foundation for the development and design of community pharmacy residency programs. ${ }^{6}$ Similar to hospital/health-system-based pharmacy residency programs, first-generation community pharmacy residencies had a substantial emphasis on managerial responsibilities. ${ }^{6}$ Many early CPRPs were started in partnership with schools and colleges of pharmacy.

In 1997, APhA updated the original programmatic essentials to reflect changes in practice and increased focus on patient care aligning more closely with changes occurring within hospital/health-system-based programs. ${ }^{7}$ In 1999, a partnership was established between APhA and the American Society of Health-System Pharmacists (ASHP) to accredit community pharmacy residencies. The first accreditation standard, the APhA/ASHP Accreditation Standard and Learning Objectives for Residency Training in Pharmacy Practice (with Emphasis in Community Care) was adopted by both ASHP and APhA in 1999, mirroring the ASHP pharmacy practice residency standard, focused on program requirements in the practice areas of practice foundation skills, direct patient care, drug information/drug policy, and practice management. ${ }^{7}$ New CPRP standards were developed and implemented in 2007 that incorporated ASHP's new terminology of "Postgraduate Year One (PGY1)" residency training and included the same outcome areas as the 2005 ASHP PGY1 standard.

The current ASHP PGY1 Pharmacy Residency Program (PRP) Standard was approved in $2016 .{ }^{8}$ In preparation for the development of new PGY1 CPRP standards, $\mathrm{APhA}$ convened stakeholders to define the future vision and direction of CPRP training and establish an action plan to achieve the vision. ${ }^{7}$ The stakeholder group envisioned a broader standard that would accommodate all types of emerging community-based practices by focusing on requirements for training the pharmacist as a patient care provider. The focus would be on the knowledge, skills, abilities and competency areas required for a residency graduate to effectively serve as a community-based patient care practitioner rather than emphazing the practice setting. The "PGY1 CPRP Standard and Competency Areas, Goals and Objectives" standards were approved in 2016 and implemented in July $2017 .{ }^{9}$
Over the last 30-plus years, the number of CPRPs has increased substantially. Throughout the 1990s new programs were introduced while others closed with about 30 in existence by the end of the millennium. ${ }^{10}$ As the first programs became accredited in the early 2000 s, opportunities emerged for grant support for the implementation of new programs. ${ }^{10}$ By 2007, program expansion continued sporadically, and 42 programs were in the accreditation process with an additional unknown number of programs outside of the accreditation pool. ${ }^{10}$ However, there has been significant expansion in CPRPs over the last 10 years, despite not being eligible for consistent funding streams such as the Medicare Direct Graduate Medical Education pass-through funding dollars that are available to many PGY1 hospital/health system residency programs. ${ }^{2}$ Using 2018 National Matching Service (NMS) data to compare PGY1 CPRPs with PGY1 PRPs, there are 208 programs with 268 positions vs. 1,137 programs and 3,201 positions, respectively. From these numbers, CPRPs represent $14.2 \%$ of programs and $7.3 \%$ of positions as reported in the 2018 match. ${ }^{1}$ However, data is lacking on the number of unaccredited CPRPs.

\section{Current PGY1 Community-Based Phamacy Residency Accreditation Standard}

The development and implementation of the 2016 APhA/ASHP PGY1 CPRP Accreditation Standard and Competency Areas, Goals, and Objectives represents a significant advancement. Extensive public dialogue and consensus building was used to create standard competency areas, goals and objectives in which programs can train residents as patient care providers in communitybased settings.

The primary purpose of PGY1 CPRP Standard is to provide education and training to develop communitybased pharmacist practitioners with the necessary skills to serve as pharmacy leaders who provide team-based quality patient care services wherever needs arise to improve the health of communities. ${ }^{11}$ Emanating from this flexibility, the types of practice settings choosing to use the PGY1 CPRP standard continues to expand (Table 1). In fact, the standard's intent is to develop practitioners who can serve patients anywhere in their communities. Examples of CPRP patient care services are in Table 1.

\section{Comparison of PGY1 Community-Based to PGY1 Pharmacy Residency Programs}

For all PGY1 pharmacy residency programs: pharmacy (2016), community-based (2017) or managed care (2017), the competency areas for education and training are intentionally uniform. ${ }^{12}$ While the types of patients, settings of care, and types of care provided vary, the main 


\section{American Journal of Pharmaceutical Education 2019; 83 (4) Article 7245.}

Table 1. Types of Practice Settings and Patient Care Services in PGY1 Community-Based Pharmacy Residency Programs

\begin{tabular}{ll}
\hline Practice Settings & \multicolumn{1}{c}{ Services $^{\mathbf{a}}$} \\
\hline Traditional community-based pharmacies & Medication Therapy Management services \\
Independent & Appointment-Based Medication Synchronization (ABMS) \\
Supermarket & Chronic disease/chronic care management \\
Chain & Patient education programs \\
Outpatient pharmacies in health-systems & Prevention programs \\
Home care pharmacies & Acute self-care and triage \\
Specialty pharmacies & Self-care \\
Federally qualified health care centers & Health and wellness \\
Free clinics & Immunizations \\
Office-based practices & Screenings \\
Assisted living facilities & Smoking cessation \\
& Weight management \\
& Contraception \\
& Annual wellness visits \\
& Point-of-care testing \\
& Pharmacogenomics \\
& Travel health \\
& Fall prevention \\
& Functional medicine \\
& Transitions of care \\
& Telehealth \\
\hline
\end{tabular}

PGY1 = Postgraduate Year One

${ }^{\text {a }}$ Not all possible community-based pharmacy services are listed

${ }^{\mathrm{b}}$ Maybe under collaborative practice

purpose is the development of the resident as a patient care provider. All three standards require two-thirds of the residents' training to be completed in the area of patient care.

Because the PGY1 PRP is likely the most familiar to most faculty mentors, the focus of this section will be on a comparison of the 2017 Accreditation Standards and Competency Areas, Goals and Objectives for the PGY1 CPRP with the 2016 PGY1 PRP. A comparison of the purpose statements from the two standards illustrates many similarities with the focus of both standards on providing broadbased training for residents as patient care providers (Table 2). ${ }^{8,11}$ The competency areas for the PGY1 PRPs and PGY1 CPRPs that accompany each of the respective accreditation standards are also essentially equivalent (Table 2). The goals and objectives are also essentially equivalent. ${ }^{12}$ PRP training is primarily focused on acute and episodic collaborative care of patients while CPRP training is on the ongoing longitudinal, collaborative care of patients.

The primary differences between the PGY1 CPRP and PRP are longitudinal experiences, developing and implementing patient care services, advocacy, and community service. Unlike short rotational experiences (four to eight weeks), PGY1 CPRPs are primarily longitudinal (three to 12 months) experiences. Longitudinal care requires unique relationship skills with patients, caregivers, other health care providers within the community to improve patient care. CPRP residents are required to create or enhance a patient care service, including writing a business and marketing plan for experience with implementing and evaluating community-based patient care services. This skill is generally not a focus in a PGY1 PRP. Leadership and advocacy skills are incorporated into residencies to help advance the role of community-based practice. Residents are also required to participate in community service to engage with the communities in which they serve.

\section{The Need for Community-Based Pharmacy Residency Education and Training}

To adequately prepare a workforce of pharmacists for present and future roles as patient care providers, it is imperative that individuals be trained in the scope of patient care they will be providing as practitioners. Additionally, supported by workforce data, $60 \%$ of new graduates are entering community-based practice and when communitybased practice is more broadly defined to include practices outside the walls of an acute care hospital or skilled nursing facility, the percentage is even higher. ${ }^{13}$ With the majority of patient care being shifted from inpatient to community-based care, and momentum building for pharmacist provider recognition under Medicare, it makes sense for the workforce to receive training within this sector. 


\section{American Journal of Pharmaceutical Education 2019; 83 (4) Article 7245.}

Table 2. Comparison of the Purpose and Competency Areas Between PGY1 Pharmacy and PGY1 Community-Based Residencies

\begin{tabular}{|c|c|}
\hline PGY1 Pharmacy ${ }^{8,12}$ & PGY1 Community Based ${ }^{11,12}$ \\
\hline $\begin{array}{l}\text { Purpose: To build upon the Doctor of Pharmacy (PharmD) } \\
\text { education and outcomes to contribute to the development } \\
\text { of clinical pharmacists responsible for medication-related } \\
\text { care of patients with a wide range of conditions, eligible } \\
\text { for board certification, and eligible for postgraduate year } \\
\text { two (PGY2) pharmacy residency training. }\end{array}$ & $\begin{array}{l}\text { Purpose: To build upon the doctor of pharmacy (PharmD) } \\
\text { education and outcomes to develop community-based } \\
\text { pharmacist practitioners with diverse patient care, } \\
\text { leadership, and education skills who are eligible to pursue } \\
\text { advanced training opportunities, including postgraduate } \\
\text { year two (PGY2) residencies and professional certifications. }\end{array}$ \\
\hline $\begin{array}{l}\text { The following competency areas and all associated } \\
\text { educational goals and objectives are required by the } \\
\text { Standard and must be included in the program's design: } \\
\text { Patient care } \\
\text { Advancing practice and improving patient care } \\
\text { Leadership and management } \\
\text { Teaching, education, and dissemination of } \\
\text { Knowledge }\end{array}$ & $\begin{array}{l}\text { The following competency areas and all associated educational } \\
\text { goals and objectives are required by the Standard and must } \\
\text { be included in the program's design: } \\
\text { Patient care } \\
\text { Advancing community-based practice } \\
\text { Leadership and management } \\
\text { Teaching, education, and dissemination of } \\
\text { Knowledge }\end{array}$ \\
\hline
\end{tabular}

PGY1 $=$ Postgraduate Year One

Furthermore, ambulatory care pharmacy practice which includes community-based pharmacy practice has been recognized as a specialty by the Board of Pharmacy Specialties validating the need for advanced training.

Currently, there are not enough PGY1 residency programs for individuals who would like to complete one with Hammond and colleagues finding that $37.1 \%$ of graduates are planning to pursue postgraduate training. ${ }^{14}$ The 2018 NMS Data report 1,925 (1,666 2018 graduates and 259 pre-2018 graduates) unmatched student pharmacists for PGY1 residency training. ${ }^{1}$ At the 2011 residency expansion conference hosted by ASHP, a topic of discussion was providing sufficient residency training opportunities to meet the needs of new graduates. One of the conclusions was the need for more community-based residency programs. ${ }^{15}$

While many of the recommendations from ASHP's residency expansion conference have been implemented and the number of PGY1 programs overall has substantially increased, the growth of community-based programs continues to be insufficient. ${ }^{14}$ Despite efforts to expand CPRPs and positions, there are only $268 \mathrm{APhA}$ ASHP Accredited CPRP positions for a practice sector that comprises $60 \%$ of the profession. As health care continues to evolve; the need will increase for highly trained community-based pharmacist practitioners (CPP). ${ }^{16}$

A CPP describes a pharmacist who routinely provides enhanced patient care services within the community. ${ }^{16}$ Common types of services provided by CPPs include medication optimization, wellness services (eg, immunizations, screenings, and smoking cessation), management and monitoring of acute and chronic conditions, transitions of care, coordination of care and population health. In addition to providing care in their communities, CPPs are working in health care teams and empowering patients. The CPP documents, communicates and collaborates to optimize the care of patients. ${ }^{16}$ CPPs have skills and expertise to develop sustainable services based on the needs of patients and their communities. ${ }^{16}$

While PGY1 CPRP training is not a prerequisite to becoming a CPP, these programs can assist in preparing graduates to serve in these roles through accelerated skill and competency development. The result is a PGY1 CPRP graduate who is a competent and proficient CPP.

As the profession continues to push for provider status and with the expansion of patient care services in community-based settings, community-based pharmacists will have limitless opportunities. CPPs will contribute to the transformation of the profession, providing access to health care services for patients in the communities they serve. The patient care services provided by CPPs, when and where the patients need care, will be key in patients achieving optimal medication and health outcomes and will firmly establish these individuals as essential health care providers on the health care team. Increasingly the contributions of CPPs are being recognized with Victor and colleagues describing the impact of CPPs on blood pressure control by meeting patients wherever they may be -- even in the barbershop. ${ }^{17}$

\section{The Impact of PGY1 Community-Based Pharmacy Residency Education and Training}

PGY1 CPRPs prepare residents for entry into a PGY2 residency program or into practice. PGY1 CPRPs have been identified as a pathway to ambulatory care practice, which includes community-based pharmacy practice and many graduates are seeking board certification as an ambulatory 


\section{American Journal of Pharmaceutical Education 2019; 83 (4) Article 7245.}

care pharmacist. ${ }^{18,19}$ Graduates of CPRPs are leaders in the profession and community, visionaries, and disruptive innovators. These individuals are providing high quality community-based care by performing advanced clinical assessments, triaging and providing physical assessments, and ultimately, managing a patient's medication therapy. ${ }^{7,16,18}$

A review of the literature supports the impact that CPRPs are having on the profession. Hohmeier and colleagues reported current positions of CPRP graduates including 34\% clinical pharmacist (patient care specialist, ambulatory care pharmacist), $16 \%$ pharmacy manager, $16 \%$ other positions and $10 \%$ split/shared academia. ${ }^{20}$ All respondents indicated that their CPRP was valuable in obtaining "their ideal position" post-graduation, with $76 \%$ stating it was very valuable and $24 \%$ stating it was somewhat valuable. ${ }^{20}$ This study supports that CPRP training assists graduates in obtaining positions beyond traditional dispensing roles, with $54 \%$ of respondents supporting this statement. ${ }^{20}$ Some companies have made substantial investments in CPRPs and built business models around positions such as clinical coordinators to provide increased opportunities for program graduates. ${ }^{20} \mathrm{Em}$ ployers' demand for CPRP-trained pharmacists will likely increase as the business opportunities expand for providing patient care services. Completing a CPRP and becoming a CPP with competencies, skills, and abilities may offer substantial differentiation as a preferential candidate in a fiercely competitive job market.

\section{Informing Student Pharmacists about Postgraduate Training Options}

Over the last several decades, the demand for postgraduate training programs has exceeded the supply. Schools and colleges of pharmacy have implemented strategies to increase student awareness of the options and better prepare them to make informed decisions. However, the structure, design, and format of information on postgraduate training programs is highly variable. McCarthy and colleagues found that promotion of fellowship and residency positions is generally introduced by most schools or colleges within the first year of professional training. ${ }^{21}$ Most respondents agreed this is an appropriate time to introduce information to allow students to make informed decisions as they complete their professional course of study. ${ }^{21}$ The methods for introduction ranged from faculty being made available to answer student pharmacist questions to formal instruction including lectures, seminars, panel discussion and interactive workshops. ${ }^{21}$ Not surprisingly, this research supports the idea that the earlier student pharmacists are aware of their postgraduate training options, the better prepared they are in making informed decisions. ${ }^{21}$
The American Association of Colleges of Pharmacy (AACP) recommends that pharmacy schools and colleges take an active leadership role to develop and enhance residencies." 22 Additionally, standard 14.4 in the "Accreditation Council for Pharmacy Education Standards 2016" (ACPE) states "doctor of pharmacy programs are called to provide students with academic advising, curricular and career pathway counseling and information regarding postgraduate education and training." 23 Hagemeier and colleagues stated "Ideally pharmacy graduates should have adequate information and exposure to a number of career paths to enable informed decision making about employment and postgraduate training paths." ${ }^{24}$ While the importance of adequately providing student pharmacists with information on postgraduate training options is firmly established, research suggests that career and postgraduate training exploration in colleges of pharmacy needs improvement. ${ }^{24}$

\section{Providing Comprehensive Residency Training Information as a Faculty Mentor}

Faculty mentors play an important role in informing student pharmacists about postgraduate training options. Student pharmacists have indicated the information obtained from faculty is helpful in guiding their overall career decisions. ${ }^{24}$ However, anecdotal data from student pharmacists interviewing for CPRPs and from residency program directors recruiting residents revealed the following about faculty mentoring: no information from faculty members about CPRPs, faculty with clear biases against community-based practice, and no faculty mentors in community-based practice. With many pharmacy career pathways, faculty members should be well versed in all postgraduate training options, and schools and colleges should have access to an adequate number of CPP faculty role models who faculty can refer student mentees to for additional information.

Faculty mentors and preceptors who consistently provide accurate information to student mentees about all of their training options may be key to students making informed career and postgraduate training choices. It is essential that faculty mentors take steps to be informed about all of the available postgraduate training programs, including community-based pharmacy residency programs. Table 3 offers key points for mentoring student pharmacists and tips and resources for mentoring.

Faculty mentors can have a substantial level of influence on their student mentees. Providing comprehensive unbiased, fair and balanced information is critical to serving in a successful mentorship role. Achieving this, however, may be more difficult than it seems. Effective mentors filter personal biases, perceptions and beliefs and are completely informed about the topic(s) on which they 


\section{American Journal of Pharmaceutical Education 2019; 83 (4) Article 7245.}

Table 3. Mentoring Students about Postgraduate Year One Residencies

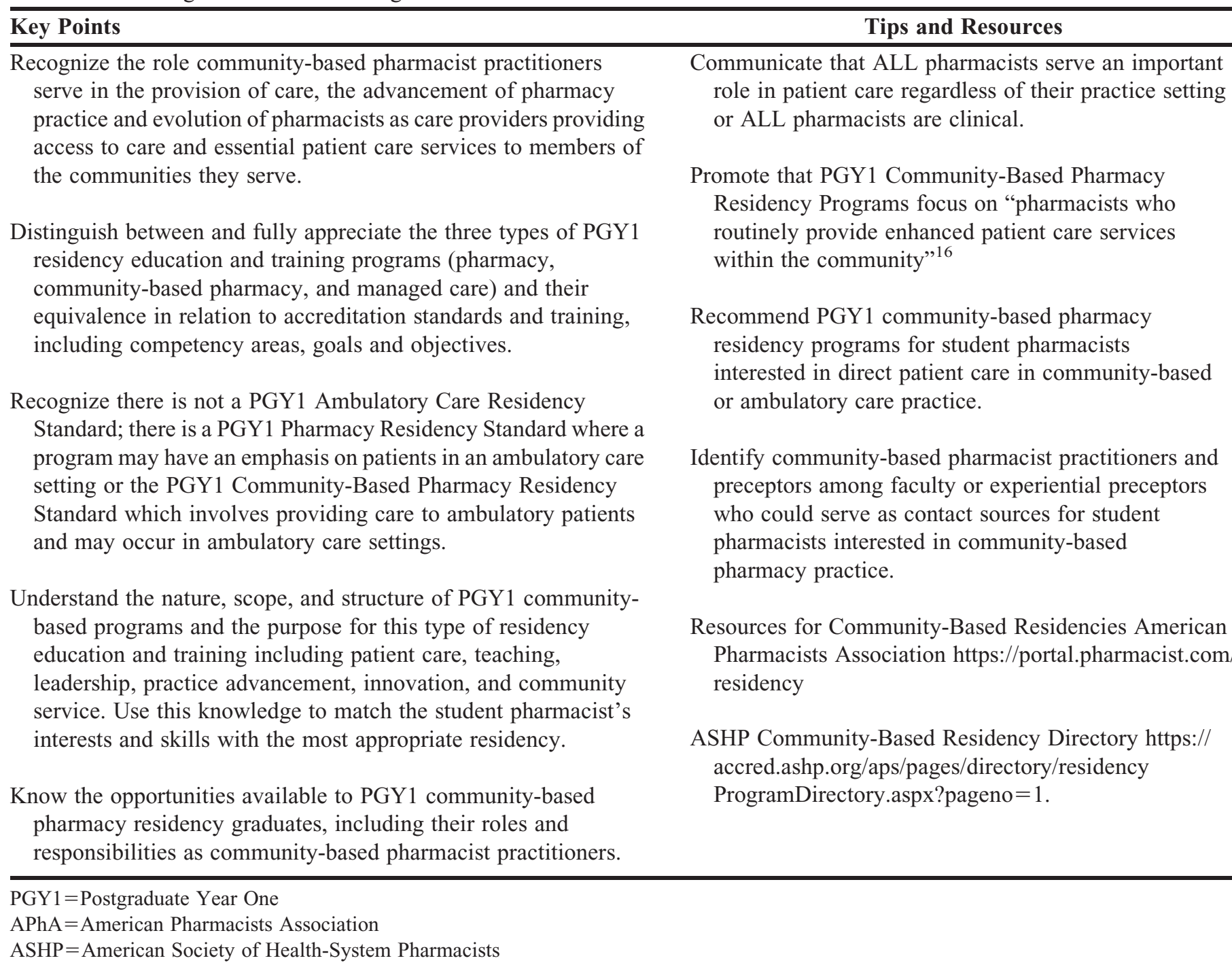

advise, including all postgraduate training options. Effective mentors can connect the passion and skills of the mentee to the pathway that is most appropriate to reach the mentee's goals.

\section{CONCLUSION}

First-year postgraduate pharmacy residency education and training has substantially evolved and expanded over the last 30 years to include options in patient care settings beyond pharmacy residencies within hospitals and health systems. Options for the first-year postgraduate residency (PGY1) training now include community-based pharmacy, managed care pharmacy, and pharmacy programs in hospitals and health systems and other settings. The requirements for PGY1 community-based residency training, accreditation, and competencies achieved are equivalent to PGY1 programs conducted in hospitals, health systems, and managed care. CPRPs offer PharmD graduates substantial opportunities to develop longitudinal patient care skills and relationships, new patient care services, leadership skills, and teaching and training skills in diverse community-based patient care environments in collaboration with other health care providers. Faculty members at schools and colleges of pharmacy have considerable influence and impact on whether students pursue postgraduate training and the type of programs they eventually pursue. It is critically important that faculty mentors bridge the current gap in informing student pharmacists about community-based pharmacy residencies.

\section{REFERENCES}

1. National Matching Services, Inc. American Society of HealthSystem Pharmacists. "Resident matching program summary of programs and positions offered and filled in the 2018 match combined phase i and phase ii." https://natmatch.com/ashprmp/stats/ 2018summpos.pdf. Accessed June 28, 2018. 


\section{American Journal of Pharmaceutical Education 2019; 83 (4) Article 7245.}

2. Stolpe SA, Adams AJ, Bradley-Baker LR, Burns AL, Owen JA. Historical development and emerging trends of community pharmacy residencies. Am J Pharm Educ. 2011. 75(8):Article 160.

3. Clark T. Celebrating 50 years of advancement in pharmacy residency training. Am J Health-Syst Pharm. 2014;71:1190-1195. 4. A residency in community pharmacy practice: is there a need? Am Pharm. 1983; NS23(5):18e19.

5. American Pharmacists Association. Online policy manual. https://www.pharmacist.com/policy-manual. Accessed August 14, 2017.

6. Covington TR, Davis RE, Roberts RW. APhA community pharmacy residency program: programmatic essentials. Am Pharm.1986; NS26(4):34e43.

7. Skelton JB, Owen JA. American Pharmacists Association. Developing a vision and strategic action plan for future communitybased residency training. J Am Pharm Assoc. 2016 Sep-Oct. 45(5):584-589.e1

8. American Society of Health-System Pharmacists.Accreditation standards for pharmacy residencies. https://www.ashp.org/ Professional-Development/Residency-Information/ResidencyProgram-Directors/Residency-Accreditation/AccreditationStandards-for-PGY1-Pharmacy-Residencies. Accessed June 28, 2018.

9. American Pharmacists Association/American Society of HealthSystem Pharmacists. PGY-1 Community-Based Pharmacy Residency Accreditation Materials. www.pharmacist.com/residencyaccreditation. Accessed June 28, 2018.

10. American Pharmacists Association Internal Community Pharmacy Residency Databases. Accessed September 14, 2017. 11. American Pharmacists Association/American Society of HealthSystem Pharmacists. Accreditation Standard for Postgraduate Year One (PGY1) Community-Based Pharmacy Residency Programs. www.pharmacist.com/residency-accreditation. Accessed June 28, 2018.

12. American Society of Health-System Pharmacists. PGY1 competency areas. https://www.ashp.org/Professional-Development/ Residency-Information/Residency-Program-Directors/ResidencyAccreditation/PGY1-Competency-Areas. Accessed January 2, 2018.

13. Pharmacy Workforce Center. Final report of the 2014 national pharmacist workforce study. https://www.aacp.org/sites/default/files/ finalreportofthenationalpharmacistworkforcestudy2014.pdf. April 8, 2015. Accessed May 1, 2019.
14. Hammond DA, Oyler DR, Devlin JW, Painter JT, Bolesta S, Swanson JM, et al. Perceived motivating factors and barriers for the completion of postgraduate training among American pharmacy students prior to beginning advanced pharmacy practice experiences. Am J Pharm Educ. 2017;81(5):Article 90.

15. American Society of Health-System Pharmacists. Expanding the number of positions for pharmacy residents: highlights from the pharmacy residency capacity stakeholders' conference. Am J HealthSyst Pharm. 2011;68:1843-1849.

16. Bennett M, Goode JV. Recognition of community-based pharmacists practitioners: essential health care providers. $J \mathrm{Am}$ Pharm Assoc. 2016 Sep-Oct;56(5):580-583.

17. Victor RG, Lynch K, Blyler C, et al. A cluster-randomized trial of blood-pressure reduction in black barbershops. $N$ Engl J Med 2018;378:1291-1301.

18. Westberg SM, Beatty SJ, Corona AR, et al. Residency pathways to ambulatory care practice: essential insights for students, residents, and educators. J Am Pharm Assoc. 2017; e1-e5. https://doi.org/ 10.1016/j.japh.2017.08.013. Accessed June 28, 2018.

19. Bonner L. Board certification for community pharmacists grows alongside clinical services. Pharmacy Today 2017; 23:39. https:// www.pharmacytoday.org/article/S1042-0991(17)31796-6/fulltext. Accessed June 28, 2018.

20. Hohmeier KC, Borja-Hart N, Cooper M, Kirby J, Fisher C. Training and retaining community pharmacy leaders: career pathways after completing a PGY1 community pharmacy residency affiliated with a supermarket chain. J Am Pharm Assoc. 2017;57:82-85.

21. McCarthy BC, Weber LM. Update on factors motivating students to pursue residency and fellowship training. Am J HealthSyst Pharm. 2013;70:1397-1402.

22. Lee M, Bennet M, Chase P, et al. Final report and recommendations of the 2002 AACP task force on the role of colleges and schools of pharmacy on residency training. Am J Pharm Educ. 2004;68(1):Article S2.

23. Accreditation Council for Pharmacy Education. Accreditation standards and key elements for the professional program in pharmacy leading to the Doctor of Pharmacy degree (Standards 2016). https:// www.acpe-accredit.org/pdf/Standards2016FINAL.pdf. Published February 2015. Accessed August 14, 2017.

24. Hagemeier NE, Murawski MM. Junior pharmacy faculty members' perceptions of their exposure to postgraduate training and academic careers during pharmacy school. Am J Pharm Educ. 2012; 76(3):Article 39. 